\title{
The Impact of Employee Engagement on Employee Retention: The Role of Psychological Capital, Control at Work, General Well-Being and Job Satisfaction
}

\author{
Tehseena Ashraf (Corresponding author) \\ Karachi University Business School, University of Karachi, Pakistan \\ E-mail: ashraftehseena@gmail.com \\ Danish Ahmed Siddiqui \\ Karachi University Business School, University of Karachi, Pakistan \\ E-mail: daanish79@hotmail.com
}

Received: February 23, 2020 Accepted: March 18, 2020 Published: March 20, 2020

doi: 10.5296/hrr.v4i1.16477 URL: https://doi.org/10.5296/hrr.v4i1.16477

\begin{abstract}
Employee engagement and retention is a promising area in management as well as psychology. The purpose of this paper is to examine the effects of employee engagement (EE) on their retention (ER). We proposed a theoretical framework model explaining how employee engagement affects their retention. The original model linked engagement with control at work (CAW) and general well-being (GWB) through psychological capital (PsyCap). We extended this model by linking CAW and GWB to employee retention. We further added job satisfaction (JS) as a mediator between EE and ER. To establish its empirical validity, we conducted a survey from 200 employees working in different companies in Pakistan by using a close ended likert scale type questionnaire. Data was analyzed using confirmatory factor analysis and structural equation modeling. Findings suggested a positive significant relationship between EE and ER. PsyCap, CAW and JS play a significant mediator role for EE and ER, only GWB does not mediates the relationship between EE and ER. This research will help in understanding how to retain employees and mounting their psychological capital through training and development, since when employees will be happy and motivated, they can perform well and will have job satisfaction. As a result, the level of intention of employees to leave would be low. This study is
\end{abstract}




\section{MInstitute ${ }^{\text {Macrothink }}$}

preliminary the first to investigate the association between EE and ER through many other constructs (PsyCap, CAW, GWB and JS) in the Pakistani context.

Keywords: Employee engagement, Psychological capital, Control at work, General well-being, Job satisfaction, Employee retention

\section{Introduction}

\subsection{Background of the Study}

The idea of employee engagement has emerged in gaining recognition among professional health psychologists due to its positive impact on employee's well-being and control at work (Shuck, 2011). An astounding 90 percent of the workforce thinks, that a policy on employee engagement, would help to improve their general well-being (Bahreini, 2015). Engaged workers are more dynamic, enthusiastic and captivated than non-engaged employees.

A study by (Luthans, 2013) recommends that these engaged workers are vastly creative and organizations should channel their energies in such a way that it stimulates their well-being and greater CAW. Although there is an uncertain connection between staff contentment and efficiency, there is a common conformity as well, that happy employees are productive (Diener, 2008; Wright, 2004).

First, engagement has become an important area for scholars because engaged employees are more concerned about their jobs, they are self-motivated and go ahead of what is anticipated from them to help the organization survive (Bakker, 2008). Employees who are contented with their careers and who are engaged in their work are expected to be happy individuals in their personal lives as well. Furthermore, job satisfaction, which is considered as an alternative of one's supposed quality of work life, has been a vital standard for evaluating an individual's career as a whole (Judge, 1995). The Study of (Gattiker, 1988) explained career satisfaction as assessment of an individual's perception of pay scale, and the level of challenge and job security in contrast of his/her accomplishment. With regard to well-being, the scholar (Lyubomirski, 2001) has related the term with happiness. These happy individuals are vigorous, approach oriented, highly attracted in their work and determined in the face of complexity. According to (Luthans, 2007), an individual's optimistic psychological state of mind is psychological capital. Many front line jobs are considered as threefold, with demands from many sides like from customer, peers, and managers. Individuals with high psychological capabilities can cope up with these numerous demands simultaneously and can easily invest their energies in work role (Luthans, 2013), while on the other hand, increasing their well-being and control at work (Nguyen, 2012).

The modern place of work is characterized by uncertainty and complexity. In such a demanding scenario of the workplace, only those employees who are optimistic, positive and highly flexible can survive and perform. Psychological Capital is an employee's personal resource that keeps them positive and confident. Also, these individuals can implement good control over their work as they are quite determined about their goals (Luthans, 2016). Such control on work enables these individuals to encompass valuable personal time with family. Hence, it may be concluded that workers with high psychological capital are fulfilled with their work effort and with their overall life, which brings general well-being (Avey, 2010).

Talent retention is another growing concern for today's dynamic organizations, with the 
pressure to have strategies for employee engagement in order to reduce turnover intention. The reason why retention is of important concern is that when an employee leaves, it brings a huge cost to the company for recruiting a replacement. In addition, the morale of other team members goes down when one leaves the company (Vigoda, 2000). Organizations need to be proactive about retention strategies. The reasons why employees leave may be voluntary uncontrollable or in voluntary controllable. Focusing on employee retention should be an organization's agenda otherwise valuable resources will be lost, leaving behind them a negative feeling and low morale (Festing, 2014). The current study will provide a meaningful implication on understanding the impact among different variables, which were never integrated and studied before in Pakistan.

\subsection{Problem Statement}

Positive psychology and mental well-being plays a vital role in today's work environment. Workers now look for jobs that keeps them engaged and motivated, that offer flexibility, growth, and promotion. In addition, long working hours, stress and work pressure, lack of work-life balance and lack of commitment gives more importance to study about the ways employee engagement could be increased at the workplace and how the company polices can be changed to retain employees. The current study aims to focus on positive psychological behavior and its role in revising company strategies.

Today's workplace consists of many generations. The changing character of the workforce now includes generation $\mathrm{X}, \mathrm{Y}, \mathrm{Z}$ and the millennial. Each demographic generation has its own values and norms (Cates, 2003). For example, the millennials do not stay in a similar organization for a longer period. They are more technologically savvy and need constant affirmation and motivation. This is in contrary to the generation $\mathrm{X}$, who are more loyal towards their company and usually stay in a single company for their entire career.

In this day and age, companies need to come up with certain strategies that can help them to engage employees of all levels of age and expectations. In Pakistan, the workforce majorly consists of generation $\mathrm{Y}$ and millennials. This has become quite a trend now that young employees work no more than five years in an organization, and then switch to another. With so much challenge and competition in the market place, it has become very important for organizations in Pakistan to retain their employees through effective employee engagement activities.

Despite knowing the benefits that employee engagement has on individual employee, their retention and over all organization performance, significant number of workforce experience disengagement from work they do and the organizations they work for (MacLeod, 2009). Pakistani workforce reflects changing attitudes, norms, and expectations. Different generations have different expectations in terms of what their work will offer them and what they expect from it. Besides, staff satisfied with their jobs will be easily retained and engaged. However, the part of psychological capital and general well-being in retaining employees in the organizations, and how engaged employee would have control at work, will also have an impact on their retention rate or not, needs an in depth analysis.

Hence, there is a need of empirical study specifically in the Pakistani context that would help to understand how employee turnover rate can be reduced through an increased level of 
engagement.

\subsection{Gap Analysis}

There has been some research on employee's well-being and life satisfaction earlier, which is found in various fields like community health, education, and criminal justice. However, they usually do not observe the nature and background of work, depicting just correlation results (Erdagon, 2012). In spite of the lately growing consideration, practical studies on well-being are still lacking. Former studies have merely focused on non-working populations including students, patients, children and others. Thus, it is felt that there is a research gap, due to the lack of consideration paid to workers well-being in the management field, as the literature on well-being has overlooked the work related domain (Erdagon, 2012). It has only happened in recent times that employee well-being is alleged to be connected with an individual's personal life and work related results has begun to be researched in the field of organizational behaviors and human resources.

The research of (Erdagon, 2012) has recommended an idea of workplace contentment, stating that it is based on satisfaction with one's surroundings, direction, job advancement, work distinctiveness and person's atmosphere fit. Contributing to an understanding of well-being at work. Similarly, the research of (Gupta, 2018) explains how employee engagement is linked with control at work (CAW) and general well-being (GWB) through psychological capital (PsyCap). Specifically in the healthcare industry of India. Findings indicated that PsyCap mediates completely among EE and CAW and moderately between EE and GWB.

However, the study of (Gupta, 2018) was limited for the healthcare sector in India, so the results cannot be generalized. Moreover, the role of culture was neglected as well. We Modified (M. Gupta, 2018) model to include retention in the framework. The original model linked engagement with control at work (CAW) and general well-being (GWB) through psychological capital (PsyCap). We extended this model by connecting CAW and GWB to employee retention. We further added job satisfaction (JS) as a mediator between EE and ER. This will give a more detailed picture by incorporating the effect of other factors like employees satisfaction relevant to the generation. Currently, there has been limited research conducted in Pakistan on employee engagement and retention. This research will not only see the impact between these two variables however, it will also include the mediating role of PsyCap, GWB, CAW and JS.

\subsection{Research Objectives}

The objective of this study is to empirically test the impact of employee engagement on employee retention and to see how different variables such as psychological capital, control at work, general well-being and job satisfaction mediates with each other and among variables in Pakistani context. In this study we are investigating that how employee engagement (EE) impacts on employee retention (ER) and how Psychological capital (PsyCap), control at work (CAW), general well-being (GWB) and job satisfaction (JS) mediates between the two variables. Even though, employee engagement, job satisfaction and employee well-being have specific and significant affiliation with each other. Though, in the current study we consider them to be distinctive constructs. 


\subsection{Research Question}

1) How will PsyCap affect the relationship between EE and ER, between EE and CAW, between EE and GWB and between EE and JS?

2) How will GWB affect the relationship between EE and ER and between PsyCap and ER?

3) How will CAW affect the relationship between EE and ER and between PsyCap and ER?

4) How will JS affect the relationship between EE and ER, between PsyCap and ER?

\subsection{Significance}

The role of employee engagement cannot be neglected in today's workplace. In order to make employee content and stay within their organization for a longer period of time, employers need to understand the importance of engaging employees. Hiring workers with high level of psychological capital, providing resources to increase their well-being and making them satisfy for the jobs through different means is as necessary as anything because employees are assets that cannot be copied, however, if not provided with proper opportunities they intend to leave.

This study will help managers to recognize how employee level of engagement will impact their retention and how other construct will catalyze this relationship (PsyCap, GWB, CAW and JS).

Engagement is not only taking a year end survey, however, it is something that goes on for the whole year and each day at the job with an employee. This study will help managers and organizations to understand that how to make engagement the core of their corporate strategy to achieve its objectives and to meet the demands of diversified workforce in Pakistan in order to retain them. This has been backed by (MacLeod, 2009) that the outcomes of highly engaged employees include higher performance, lower level of intention to quit and sound business acumen and sense.

The current research will contribute in building the theoretical knowledge as it will incorporate new factors affecting engagement level of an employee as well as to be able to retain employees in organizations in a demanding environment. The generational gap within organizations makes it difficult for leaders to come up with strategies that will manage staff from all age brackets. Even many organizations in Pakistan are still unable to accept the fact that employee engagement and retention are and should be the part of overall HR KPI's and matrix as organizations performance is associated with both of these variables.

Furthermore, this study will enable the HR and OD professionals to incorporate strategies that can build employees level of engagement. Certain competencies can be included to identify the individuals before hiring and to know if they are psychologically positive or not. OD can work on cultural aspect by making culture more conducive for all new employees as well as old employees.

\section{Literature Review and Hypothesis Development}

This has been argued by many scholars that engaged workers need to be psychologically strong to live a high quality life (Fredrickson, 2009) in terms of well-being and CAW to attain personal and organizational goals (Richman, 2006). In the below section, we will review the study construct and subsequently drive the hypothesis. 


\subsection{Employee Engagement and Employee Retention}

According to (Law, 1998), engagement is a multidimensional construct. It is the expression of an individual's complete self (physical, emotional and cognitive) in their job roles (Kahn, 1990). It consists of three major facets that are:

(1) Vigor: which is the work related energy and resilience that an individual possesses. Engaged employees are flexible when hard times arise, they can easily cope up with pressure and know how to use their time and energy to complete each task. Employees high in vigor are good team player and support to other team members when required. With their stimulating and brisk attitude, they do every task with immense zeal (i.e. physical and behavioral engagement).

(2) Dedication: engaged employees are highly involved in their task, and have considerate quest of work. They feel that their work is extremely imperative for the organization and its success. These workers feel pride in the work they do and have strong job identity and job significance. These are also aware about how their job will affect other jobs in the organizations and they know their responsibilities and duties fully. They know how to get a task completed, they put their full energy and potential in any new task assigned to them.

(3) Absorption: it is the degree to which the employees are entirely alert and immersed in their task, which they find captivating and appealing. These employees are fully concentrated and happy while performing work, it is that state whereby the time of an employee passes very rapidly and one finds it hard to detached oneself from assigned work. With the presence of these three constructs, it is believed that the employee is engaged.

According to (Harter, 2002), engaged employees have a tendency to demonstrate positive organizational outcomes which includes customer satisfaction, efficiency, increased profits, and lower turnover intentions (Harter, 2002), higher organization commitment (Schaufeli, 2004) and work-family satisfaction (Bakker, 2008). (Maslach, 2001), analyzes why employee feel burn out by taking a contemporary approach to which he said that the employee being engaged at their work is the antidote of burnout. Studies on the construct job engagement to date have tried to identify the key drivers of engagement. The Study of (Schaufeli, 2004) discovers that there are job resources that act as job motivators, which brings engagement and through which positive attitude, high productivity and good mental health is depict in engaged employees. These empirical results suggest that engaged employees are psychologically strong and vice versa. They are resilient in hard times and they have control over their work with career satisfaction, and this may lead to low turnover intention.

According to (Mitchell, 2001), when an employee thinks to quit any organization due to poorly designed work polices, role conflicts, least motivation, the concentration of same work, lack of growth opportunities, lack of training and development, issues with management or any other voluntary reason, is called turnover intention. Reports suggest that engaged and committed employees can generate many benefits for the organization such as lower absenteeism and reduce turnover (de Lange, 2008). Due to extreme competition from the market, companies need to come up with different strategies to retain employees, otherwise organizations will be prone to many issues. Retention strategies referred by different scholars comprise financial reward, job enlargement, training and development opportunities, work 


\section{MInstitute Macrothink $^{\text {Int }}$}

life balance, and supportive work environment (Ghosh, 2013). Other scholars present retention strategies as employee engagement (Palmer, 2012), career development (Agarwala, 2003) and learning attitudes (Kyndt, 2009). As per former literature, some of the reasons why an employee aims to leave an organization are the lack of vigor, dedication and absorption in one's work- life. Hence, the below hypotheses can be stated:

\section{H1. There is an impact of employee engagement on employee retention}

\subsection{PsyCap}

Organizations in current times are trying to increase psychological capital beyond financial capital (what you have), human capital (what you know), and social capital (who you know) (Luthans, 2004). It is broadly defined as a creature's positive state of development related to "who you are" and "what you can become" (Luthans, 2007). It consists of four dimensions:

(a) Self - efficacy: take on a challenging task and implementing it through enough self-confidence. It is basically the control of oneself on its behaviors, level of motivation and social environment. Belief of an individual in his or her capability to show behaviors that can produce specific performance attainment. Believing in one self to do certain tough and challenging task and completing those tasks efficiently.

(b) Optimism: it is about having an optimistic view point on being victorious now and in the near future, being positive about changes taking place at the workplace and in life and taking all the changes optimistically and believing that success will be achieved in near future.

(c) Hope: representing determination and elasticity in achieving goals, employees aiming high about the future and expecting certain things to happen for them like achieving their assigned objectives.

(d) Resilience: being persistent in the face of difficulty and adversity, facing the difficult time with courage and determination and being cheerful during tough time considering that it is also the part of learning and shall pass too.

These four dimensions buildup the psychological capital of individual. Individuals with high level of psychological capital are very important for organizations as the work pressure and work demands are increasing each day. Today, many companies are opting towards lean management style, restructuring the entire layer of management, and bringing an overall organizational change. Employees with high level of PysCap can be able to deal with such drastic changes in the workplace.

(Luthans, 2007) Study further suggests that PsyCap is the higher order and comprehensive structure for understanding and capitalizing on human assets in the organization. Many related factors that influence the level of efficacy, hope, resilience and optimism. The author further claims in his study that employees with a high level of PsyCap are more motivated and positive at work fundamentally. Work stress is managed in a much better way by a positive employee than those employees who frequently feel low and down (Gupta, 2017). Furthermore, due to certain accomplishments at work, an engaged worker may experience higher level of satisfaction and feel happy, which can ultimately leads to the state of GWB (Tinline, 2010). These achievements makes employee feel more certain at work and refill their ability of persistence and resilience. The employees are more optimistic now about the future. Hence, it can be said that because of involvement and engagement in work, employee 
experience success and positive feeling (Bakker, 2008). This will improve their special resources such as efficacy, hope, optimism and resilience (PsyCap). Further, these special resources help individual employees to assist in managing stress and pressure at work (i.e.CAW) and keep them contented and motivated in work (i.e. GWB) (Luthans, 2016). These workers are then satisfied with their work (JS) and the intention to leave the organization also decreases. Hence, the following hypotheses are proposed:

H2. PsyCap will positively mediate the relationship between employee engagement and CAW

H3. PsyCap and GWB will positively mediate the relationship between employee engagement and employee retention

H4. PsyCap and JS will positively mediate the relationship between employee engagement and employee retention

H5. PsyCap will positively mediate the relationship between employee engagement and GWB H6. PsyCap will positively mediate the relationship between employee engagement and JS

\subsection{General Well-being}

An effect-orientated evaluation of well-being is happiness that entails predominance of positive affect over negative affect (Diener, 1984). In his study, (Christopher, 1999) mentioned that a person with more positive feelings than negative, is apparent like doing well (happy), or experiencing well (i.e. individuals appraisal) and possessing higher emotional intelligence. Health, steady employment, wealth (income), encouraging relations and happy recent life events (child birth, marriage, buying house) are associated with higher GWB (Weimann, 2015). GWB means that people will have high levels of positive emotions and are satisfied with life in general. A person with a high level of GWB would be inclined by his professional experience and will be independent of his work situation to a certain extent. (Zelenski, 2008) argued in his study of happy productive workers that happy people are indeed more productive. According to (Diener, 1984) and (Erdagon, 2012) SWB involves two components: affective balance (comparisons between the level of positive and negative effects in someone's life) and views about life satisfaction. GWB is an emerging topic in the management area as today's organizations are more versatile and work hours have been increased with job complexity. GWB bring positive outcomes in employees work and personal life. Individual with a high level of GWB are supposed to be retained in the organizations for longer period of time as they are generally happy with the surrounding and whatever is going on in their life. Consequently, they take changes at workplace as positive changes. Also, they are more productive and may possess high level of PsyCap. In the current study we suppose that sense of well-being is not rigid and can be influenced by individual's intentions and related factor. We are examining GWB as an outcome of EE and PsyCap and in turn seeing its effect on ER. Hence, we have proposed the following hypotheses:

H7. GWB will positively mediate the relationship between employee engagement and employee retention

H8. GWB will positively mediate the relationship between PsyCap and employee retention

\subsection{Control at Work}

The extent to which an individual can exert control over their decisions at work is CAW. It is basically an individual's capability to control what happens in his or her work, mainly to 
influence matters that are important to his or her personal goals. In addition to this, it can also be called as autonomy in the work place, whereby an employee can have the freedom to determine what he or she can do at work and how can he or she do that work. In today's era, employees prefer jobs that provide them autonomy to make certain decisions along with responsibilities. People prefer not to be dictated but rather be encouraged in what they do by themselves, which also give rise to many positive feelings.

According to (Weigl, 2010) engaged employees can easily implement control over their work by job enlargement and by creating additional demanding responsibilities for them. Higher CAW motivates employees to achieve predefined goals. Job related results are affected by the extent to which an individual thinks positively. Researchers think that there are jobs which are critical and require greater focus and control like in health care industry (Gupta, 2016). Literature suggests that CAW is a potential consequence of EE and PysCap. EE fosters CAW (Torp, 2013). There has been a positive relationship found between these two variables. Engaged employees are cognitive vigilant and high on energy which enables them to control their work. Hence, we propose the following hypotheses:

H9. CAW will positively mediate the relationship between employee engagement and employee retention

H10. CAW will positively mediate the relationship between PsyCap and employee retention

H11. PsyCap and CAW will positively mediate the relationship between employee engagement and employee retention

\subsection{Job Satisfaction}

Job Satisfaction (JS) is a measure of career success, which means positive work related and psychological outcomes that are achieved by an individual as a result of work related experiences (Judge, 1995). It is basically the response of an employee towards his/her work experience. (Gruneberg, 1979) said that it is an emotional response towards their job, as to how they feel about their job and work conditions (Bushra, 2012). It is one of the important factors leading to success in the organization. In one study by $(\mathrm{Ng}, 2005)$, it was classified that the predictors of career success are organizational sponsorship (support from supervisor, learning and growth opportunities and organization size), human assets, steady individual differences and socio demographic variables. It is also obvious that satisfied employees show a positive attitude towards the organization, while dissatisfied shows opposite.

It is observed in the study by (Lee, 2009) that levels of dissatisfaction in jobs such as low motivation, absenteeism, grievance and high turnover are all effected by job satisfaction. Work satisfaction plays its role in bringing positive behavior among employees and hence increasing employee retention. In his study, (Lounsbury, 2003) suggest that assertiveness, carefulness, emotional toughness and extraversion were absolutely linked with career satisfaction. Hence, we suggest the following hypotheses:

H12. JS will positively mediate the relationship between employee engagement and employee retention

H13. JS will positively mediate the relationship between PsyCap and employee retention

\section{Theoretical Framework}

Research theoretical model of the study is illustrated in Figure 1 which clarifies the 
relationship between study variables.

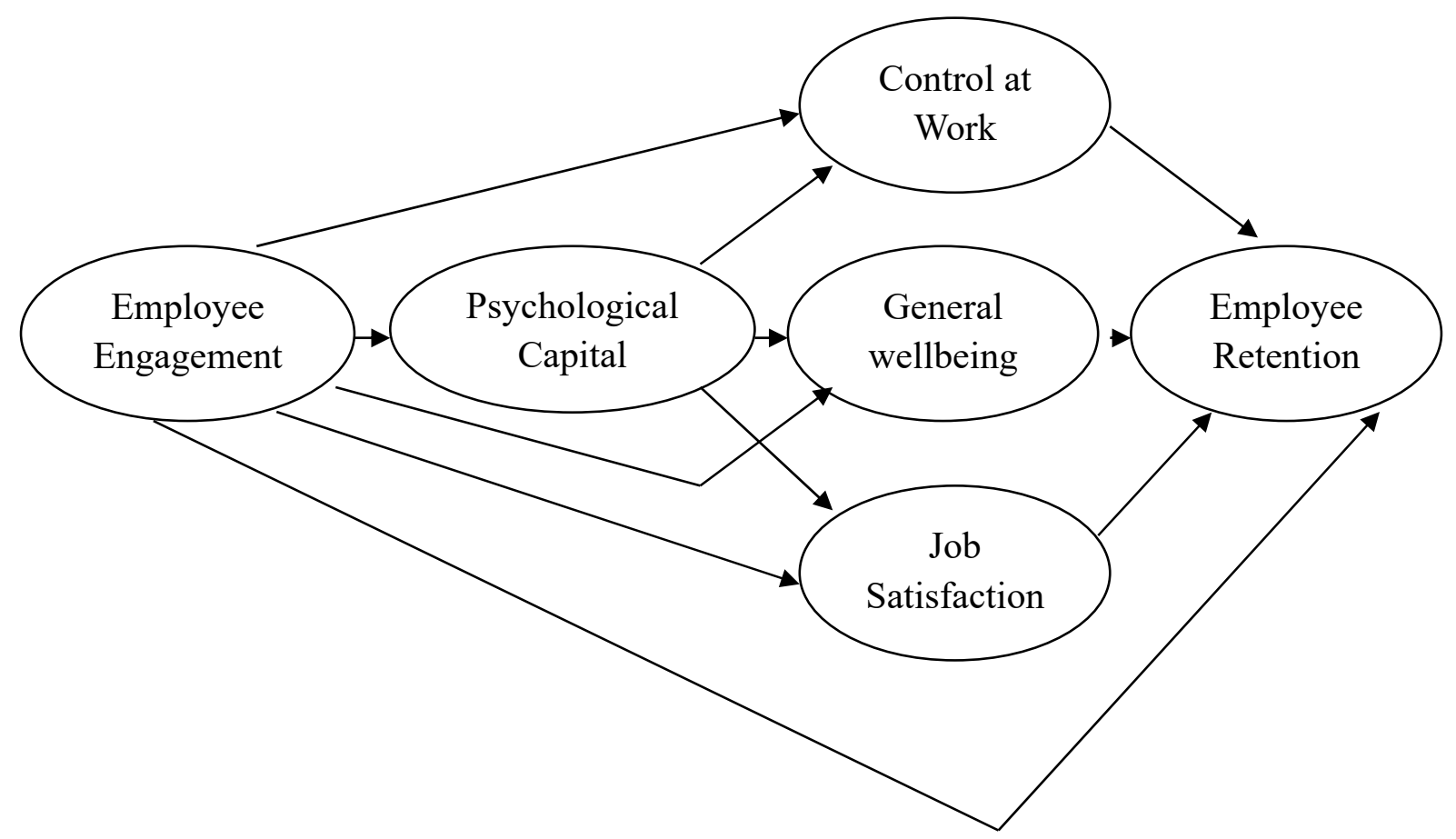

Figure 1. Study framework

\section{Methodology}

\subsection{Sample and Procedure}

The sample consists of employees working in different companies within Pakistan. The questionnaire survey was used to gather data from respondents. The questionnaires were distributed to 250 employees, while 230 were returned, out of which 200 usable responses were considered as the final sample for the study, giving a response rate of about 80 percent. The sample in this research includes 166 employees from different service companies, while 34 were from different manufacturing companies.

Table 1. Demographic profile of the study

\begin{tabular}{llll}
\hline Demography & Values & Response Number & Percentage \\
\hline Nature of Business & Manufacturing & 34 & $17 \%$ \\
& Service & 166 & $83 \%$ \\
Gender & Male & 124 & $62 \%$ \\
& Female & 76 & $38 \%$ \\
Marital Status & Married & 65 & $32.50 \%$ \\
& Single & 135 & $67.50 \%$ \\
Age & $21-30$ Years & 128 & $64 \%$ \\
& $31-40$ Years & 40 & $20 \%$ \\
\hline
\end{tabular}




\begin{tabular}{|c|c|c|c|}
\hline \multicolumn{3}{|c|}{ A Macrothink } & \multirow{2}{*}{$\begin{array}{c}\text { Human Resource Research } \\
\text { ISSN 1948-5441 } \\
\text { 2020, Vol. 4, No. } 1 \\
8.50 \%\end{array}$} \\
\hline & $41-50$ Years & 17 & \\
\hline & $51-60$ Years & 14 & $7 \%$ \\
\hline & above 60 years & 1 & $0.50 \%$ \\
\hline \multirow[t]{2}{*}{ Sector } & Private & 189 & $95.50 \%$ \\
\hline & Public & 11 & $5.50 \%$ \\
\hline \multirow[t]{4}{*}{ Education Level } & Intermediate & 3 & $1.50 \%$ \\
\hline & Graduate & 115 & $57.50 \%$ \\
\hline & Post Graduate & 78 & $39 \%$ \\
\hline & PHD & 4 & $2 \%$ \\
\hline \multirow[t]{5}{*}{ Experience } & Less than a year & 33 & $15.5 \&$ \\
\hline & 1 - 5 Years & 91 & $14.50 \%$ \\
\hline & 6 - 10 Years & 36 & $18 \%$ \\
\hline & 11- 16 Years & 23 & $11.50 \%$ \\
\hline & 16 Years and Above & 17 & $8.50 \%$ \\
\hline
\end{tabular}

The demographic variables included gender, marital status, age, education level and working experience. Most respondents were male (62 percent), among which (60 percent) were in their 30's, and (23 percent) in their 40's. The education level of respondents includes, 57 percent graduated from a university. The length of employment at the current employer is between one to five years ( 45.5 percent), between six to ten years (18 percent) and between eleven to fifteen years (11.5 percent). The age of the respondents ranges from 20 to 60 years and work experience varied from 1 to 16 years and above. In summary, most respondents were educated males working for less than five years in the service industry. Summary of the demographic profile is presented in Table 1.

\subsection{Measures}

Well established, reliable and valid scales were used to measure the data. The instruments were designed for the individual level unit of analysis. Each respondent was required to complete six measures: Employee Engagement (EE), Psychological Capital (PsyCap), Control at Work (CAW), General Well-being (GWB), Job Satisfaction (JS) and Employee Retention (ER).

EE was measured by using the items from employee engagement scale by (Schaufeli, 2006), (Cronbach's $\alpha$ is 0.857). A sample item is "I feel bursting with energy at my work". PsyCap was measured using item from (PCQ) questionnaire (Luthans, 2007). Sample items include "I always look on the brighter side of things at work" and "I feel confident contributing to discussions about the company strategy". Both CAW and GWB were measured using (Easton, 2013), CAW, 6 items, (Cronbach's $\alpha=0.845$ ): GWB, 3 items, (Cronbach's $\alpha=0.843$ ), One of the Sample item for CAW is "I am able to voice opinions and influence changes in my area of work" and a sample item for GWB is "In most ways my life is close to ideal". JS scale 
developed by (Stringer, 2006) was used for JS, a sample item is "I have the chance to work alone at my job" and Employee Retention was measured using developed scale of (Seashore, 1982) (Cronbach's $\alpha=0.886$ ) and a sample item includes "I will not change this organization easily"

\subsection{Descriptive Statistic\& Analysis}

Table 2. Descriptive statistics of the study

\begin{tabular}{|c|c|c|c|c|c|c|c|}
\hline \multirow{2}{*}{ Construct } & \multirow{2}{*}{\multicolumn{2}{|c|}{ Question }} & \multirow{2}{*}{\multicolumn{2}{|c|}{$\begin{array}{l}\text { Descriptive } \\
\text { Stats } \\
\text { Mean St. } \\
\\
\quad \text { dev. }\end{array}$}} & \multicolumn{3}{|c|}{ Confirmatory Factor Analysis } \\
\hline & & & & & $\begin{array}{l}\text { Outer } \\
\text { Loading }\end{array}$ & T Stats & $\begin{array}{l}\mathrm{P} \\
\text { Values }\end{array}$ \\
\hline \multirow{7}{*}{$\begin{array}{l}\text { Employee } \\
\text { Engagement }\end{array}$} & 1 & $\begin{array}{l}\text { I feel bursting with energy at my } \\
\text { work }\end{array}$ & 3.17 & 1.11 & 0.539 & 7.866 & 0 \\
\hline & 2 & $\begin{array}{l}\text { I can continue working for a very } \\
\text { longer period at a time }\end{array}$ & 3.275 & 1.113 & 0.745 & 16.999 & 0 \\
\hline & 3 & I feel strong and vigorous at my job & 3.465 & 1.034 & 0.789 & 19.944 & 0 \\
\hline & 4 & $\begin{array}{l}\text { Mentally, I am very resilient at my } \\
\text { job }\end{array}$ & 3.43 & 0.993 & 0.759 & 16.492 & 0 \\
\hline & 5 & $\begin{array}{l}\text { My role at job inspires me a lot and I } \\
\text { am proud of my work }\end{array}$ & 3.655 & 1.116 & 0.82 & 33.136 & 0 \\
\hline & 6 & $\begin{array}{l}\text { My job is challenging and I am } \\
\text { enthusiastic about my work }\end{array}$ & 3.61 & 1.144 & 0.803 & 29.683 & 0 \\
\hline & 7 & $\begin{array}{l}\text { It is difficult to detach myself from } \\
\text { my work }\end{array}$ & 3.285 & 1.137 & 0.672 & 15.35 & 0 \\
\hline \multirow{7}{*}{$\begin{array}{l}\text { Psychological } \\
\text { Capital }\end{array}$} & 8 & $\begin{array}{l}\text { I feel confident in helping to set goals } \\
\text { in my work area }\end{array}$ & 3.67 & 1.073 & 0.796 & 20.081 & 0 \\
\hline & 9 & $\begin{array}{l}\text { I feel confident contributing to } \\
\text { discussions about the company } \\
\text { strategy }\end{array}$ & 3.54 & 1.09 & 0.741 & 19.519 & 0 \\
\hline & 10 & $\begin{array}{l}\text { Currently, I am very enthusiastic } \\
\text { about pursuing my work goals }\end{array}$ & 3.63 & 1.069 & 0.773 & 17.655 & 0 \\
\hline & 11 & $\begin{array}{l}\text { There are lots of ways around any } \\
\text { problems }\end{array}$ & 3.585 & 1.041 & 0.744 & 19.205 & 0 \\
\hline & 12 & I see myself as successful at work & 3.515 & 1.095 & 0.8 & 15.216 & 0 \\
\hline & 13 & $\begin{array}{l}\text { When there is a setback at work, I } \\
\text { find it difficult to move on }\end{array}$ & 2.955 & 1.115 & 0.526 & 19.698 & 0 \\
\hline & 14 & I manage difficulties one way or & 3.56 & 1.047 & 0.697 & 7.639 & 0 \\
\hline
\end{tabular}


another at work

15

I always look on brighter side of things at work

I can get through difficult times at

16 work because I've experienced difficulty before

17

I feel I can handle many things at a time at this job

18

I am able to voice opinions and influence changes in my area of work

Control at work

General

Well-being

Job Satisfaction

29

19 I am involved in decisions that affect me in my own area of work

I am involved in decisions that affect area of work

21 I feel well currently

22 I am satisfied with my life

23 In most ways my life is close to ideal

24 Usually things work out well for me Recently, I have been feeling

25 reasonably considered

26

Lately, I have been feeling unhappy and depressed(r)

27

I am able to keep myself busy all the time

28

I have the chance to work alone at my job

I have the chance to tell people what to do

30 I can try new methods to do any task

31

I have the freedom to used my own judgment

32

I feel I have got timely advancement in my job $\begin{array}{lllll}3.68 & 1.09 & 0.782 & 11.724 & 0\end{array}$

$\begin{array}{lllll}3.5 & 1.095 & 0.702 & 15.826 & 0\end{array}$

$\begin{array}{lllll}3.43 & 1.089 & 0.771 & 11.569 & 0\end{array}$

$\begin{array}{lllll}3.41 & 1.083 & 0.865 & 43.632 & 0\end{array}$

$\begin{array}{lll}3.44 & 1.023 & 0.92\end{array}$

$70.697 \quad 0$

$\begin{array}{lllll}3.23 & 0.999 & 0.836 & 33.958 & 0\end{array}$

$\begin{array}{lllll}3.475 & 1.015 & 0.851 & 40.529 & 0\end{array}$

$\begin{array}{lllll}3.48 & 1.144 & 0.887 & 61.907 & 0\end{array}$

$\begin{array}{lllll}3.245 & 1.134 & 0.85 & 35.828 & 0\end{array}$

$\begin{array}{lllll}3.51 & 0.99 & 0.892 & 55.928 & 0\end{array}$

$\begin{array}{lllll}3.395 & 1.1 & 0.851 & 36.667 & 0\end{array}$

$\begin{array}{lllll}3.335 & 1.238 & 0.006 & 0.052 & 0.958\end{array}$

$\begin{array}{lllll}3.54 & 0.994 & 0.62 & 8.793 & 0\end{array}$

$\begin{array}{lllll}3.29 & 1.138 & 0.688 & 11.178 & 0\end{array}$

$\begin{array}{lllll}3.475 & 0.995 & 0.844 & 24.435 & 0\end{array}$

$\begin{array}{lllll}3.465 & 1.109 & 0.743 & 12.149 & 0\end{array}$

$\begin{array}{lllll}3.445 & 1.033 & 0.713 & 12.766 & 0\end{array}$

$\begin{array}{lllll}3.285 & 1.079 & 0.772 & 17.439 & 0\end{array}$ 


\begin{tabular}{|c|c|c|c|c|c|c|c|}
\hline & 33 & I am appreciated on my job & 3.53 & 1.053 & 0.792 & 17.975 & 0 \\
\hline & 34 & I get enough pay as per my workload & 3.08 & 1.262 & 0.705 & 15.47 & 0 \\
\hline \multirow{3}{*}{$\begin{array}{l}\text { Employee } \\
\text { Retention }\end{array}$} & 35 & $\begin{array}{l}\text { I Plan to stay in this organization for } \\
\text { next five years }\end{array}$ & 3.08 & 1.154 & 0.908 & 66.614 & 0 \\
\hline & 36 & $\begin{array}{l}\text { I will not change this organization } \\
\text { easily }\end{array}$ & 3.09 & 1.154 & 0.917 & 51.406 & 0 \\
\hline & 37 & $\begin{array}{l}\text { For me, this organization is the best } \\
\text { of all possible organization to work } \\
\text { for }\end{array}$ & 3.19 & 1.181 & 0.882 & 45.612 & 0 \\
\hline
\end{tabular}

The mean of the variables mentioned in Table 2 ranges from 2.995 to 3.68 and SD from 0.99 to 1.262. Similarly, the mean of seven items of the variable EE ranges from 3.17 to 3.655 , whereas SD ranges from 0.993 to 1.144 . The outer loading range from 0.539 to 0.820 . Outer loading above 0.7 is significant. In variable EE, outer loading of two statements are below 0.7 and the remaining five are above 0.7 , which are all significant. The $t$ statics range from 7.866 to 33.136.The $t$ statics is the value of differentiation represented in units of standard error, the higher the $\mathrm{t}$ statistic value, the greater the evidence against null the hypothesis. All the $\mathrm{P}$ values are 0.000 for the items of $\mathrm{EE}$ which is quite significant. A low p-value (normally $\leq$ 0.05 ) indicates strong proof against the null hypothesis.

Next, the mean of ten items of the variable PsyCap ranges from 2.955 to 3.68 whereas SD ranges from 1.041 to 1.115 . The outer loading range from 0.526 to 0.800 , the outer loading of two statements is below 0.7 and the remaining eight are above 0.7 which are all significant. The $t$ statics range from 7.639 to 20.081 . All the P values are 0.000 for the items of PsyCap which are quite significant.

Similarly, the mean of three items of the variable CAW ranges from 3.23 to 3.44 whereas SD ranges from 0.999 to 1.083 . The outer loading range from 0.836 to 0.920 , which are all significant. The $t$ statics ranges from 33.958 to 70.697 . All the $\mathrm{P}$ values are 0.000 for the items of CAW which are quite significant.

Furthermore, the mean of ten items of the variable GWB ranges from 3.245 to 3.51 whereas $\mathrm{SD}$ ranges from 0.99 to 1.238 . The outer loading range from 0.0006 to 0.892 , the outer loading of one statement is below 0.7 and the remaining five are above 0.7 , which are all significant. The $\mathrm{t}$ statics range from 0.052 to 61.907 . All the $\mathrm{P}$ values are 0.000 for the items of GWB except for item six which is 0.958 .

In addition to this, the mean of eight items of the variable JS range from 3.08 to 3.54 whereas $\mathrm{SD}$ ranges from 0.994 to 1.262 . The outer loading range from 0.620 to 0.844 , the outer loading of two statements are below 0.7 and remaining six are above 0.7 which are all significant. The t statics range from 8.793 to 24.435 . All the $\mathrm{P}$ values are 0.000 for the items of JS which are quite significant.

Lastly, the mean of three items of the variable ER ranges from 3.08 to 3.19 whereas the SD ranges from 1.154 to 1.181 . The outer loading ranges from 0.882 to 0.917 . The $t$ statics 
ranges from 45.612 to 66.614 . All the P values are 0.000 for the items of ER which are quite significant.

\subsection{Measurement Validation}

Table 3. Correlation of coefficient values *a fair positive relationship, **a strong positive relationship among variables

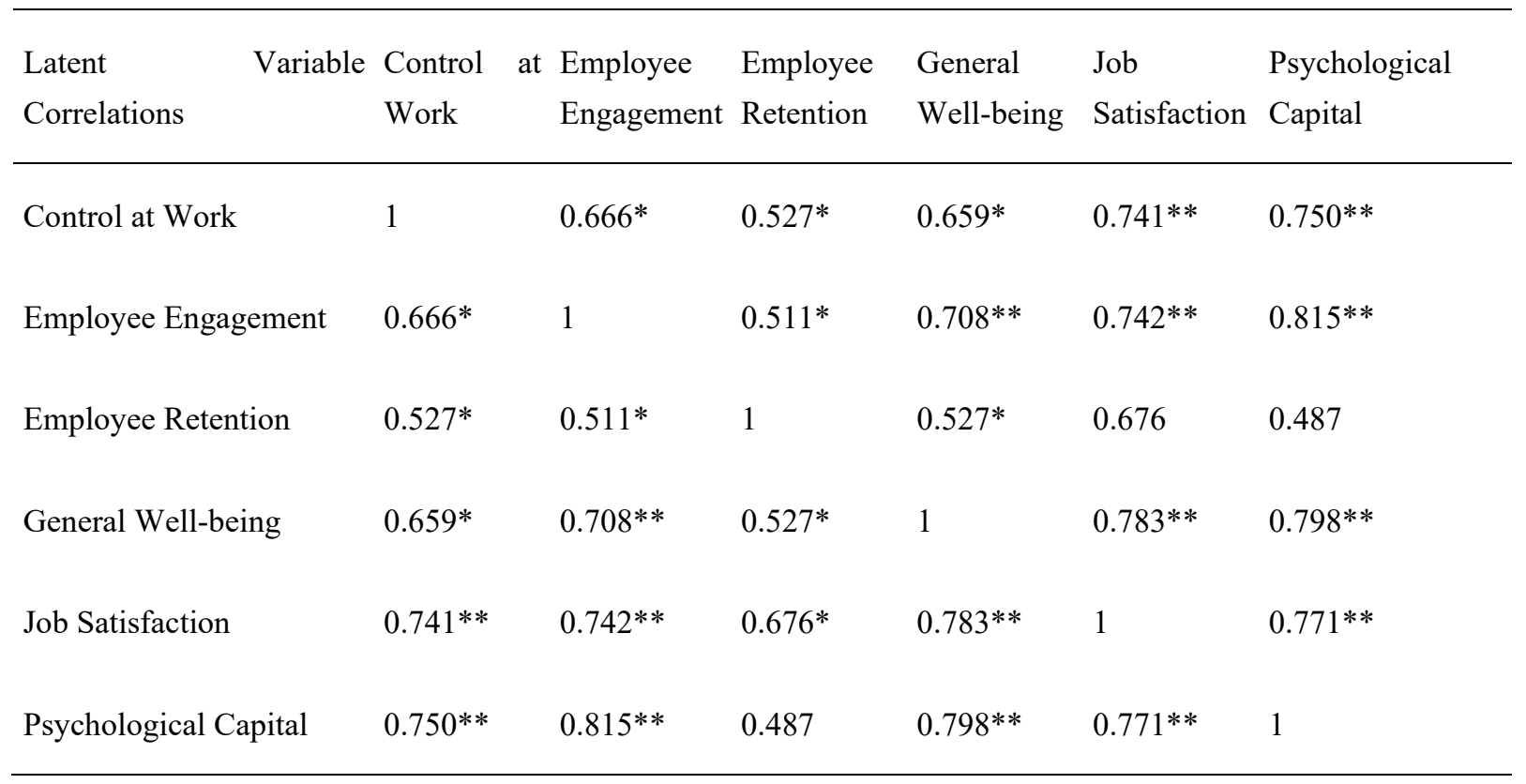

In the initial stage, the relationship of all variables in study with each other was identified through their coefficient correlation. All the major variables are positively correlating with each other as values are near to 1 .

\subsection{Data Analysis and Results}

In this part, the fallout from Partial Least Square Analysis (PLS), reliability and correlation are reported. To examine hypothesis, (SEQ) structural equation modeling is used, which is considered to be one of the strong methods to examine measurement and structural models.

The second step, includes the measurement model, which is the projected framework, and the variables validity (which includes the reliability, convergent and discriminant validity) of all variables were measured with the help of confirmatory factor analysis (CFA) using PLS Smart 3.0. The study is completed in two parts, in the first step CFA was calculated for individual variables to check its factor structure. The outcome from this step inveterate that the EE and PsyCap are multidimensional constructs, that have four and three primary factors as mentioned earlier in the literature (Schaufeli, 2006) (Luthans., 2007). Re - specification of the model was not required to improve its fit and the measurement model had a good fit to the data. CFA showed that CAW, GWB, JS and ER are unidimensional constructs. 
Table 4. Rho_A, CR and AVE Values

\begin{tabular}{lcclc}
\hline & \multicolumn{2}{c}{ Cronbach's Alpha rho_A Composite Reliability Average Variance Extracted (AVE) } \\
\hline Control at Work & 0.845 & 0.846 & 0.907 & 0.764 \\
Employee Engagement & 0.857 & 0.871 & 0.892 & 0.545 \\
Employee Retention & 0.886 & 0.889 & 0.929 & 0.814 \\
General Well-being & 0.843 & 0.915 & 0.893 & 0.626 \\
Job Satisfaction & & 1.000 & \\
Psychological Capital & 1.000 & \\
\hline
\end{tabular}

In the next step of the CFA analysis, all the latent variables were co- varied with each other in the overall measurement model (i.e. proposed theoretical model).

To examine construct validity, composite reliability was calculated and all the values were above 0.8 , equal to or greater than .80 , which is considered good for confirmatory research (Daskalakis, 2008). CR is the most vigorous determinant of reliability as contrast to Cornbach's $\alpha$. The results of the scale are reliable in the current study. Furthermore, the average variance extracted (AVE) was also premeditated to ascertain convergent reliability. The value of AVE should be greater than 0.5. AVE values of the variables EE, CAW, GWB and ER are greater than 0.5 which confirms that the variables have ample convergent validity. (Refer Table 4).

4.6 Discriminant Validity

Table 5. Discriminant validity

\begin{tabular}{lllllll}
\hline & CAW & EE & ER & GWB & JS & PsyCap \\
\hline CAW & 0.874 & & & & & \\
EE & 0.666 & 0.738 & & & & \\
ER & 0.527 & 0.511 & 0.902 & & \\
GWB & 0.659 & 0.708 & 0.527 & 0.791 & & \\
JS & 0.741 & 0.742 & 0.676 & 0.783 & & \\
PsyCAp & 0.750 & 0.815 & 0.487 & 0.798 & 0.771 & \\
\hline
\end{tabular}

Discriminate validity is defined as any single construct when differs from other constructs in the model which are meant to be related in a particular study (Carmine, 1979). Discriminate validity results are acceptable when the variables have an AVE loading more than 0.5 which indicates that a minimum $50 \%$ of the variance was taken by the construct (Chin, 1998). Discriminate validity is recognized if the elements, which are in diagonal, are considerably higher than those values, which are in off-diagonal in the parallel rows and columns. Discriminant Validity analysis are being conducted to examine whether non-related ideas or 
measurements are in fact unrelated or not. A useful estimation of discriminant legitimacy demonstrates that a trial of an idea isn't exceptionally associated with different tests intended to quantify hypothetically various ideas. As per the result of the current study, the top numbers (which are the square root of AVE) in each factor column are almost higher than the values (correlations) below it, so there exists a disriminat validity. However, the correlation value of JS and PsyCap where EE is at the top and correlations of PsyCap with GWB on top are higher than AVE values. (Refer Table 5).

\subsection{Model fit measures}

Table 6. Model fit measures

\begin{tabular}{lll}
\hline & Saturated Model & Estimated Model \\
\hline SRMR & 0.064 & 0.074 \\
d_ULS & 2.914 & 3.853 \\
d_G & 1.168 & 1.241 \\
Chi-Square & $1,199.953$ & $1,254.286$ \\
NFI & 0.793 & 0.783 \\
\hline
\end{tabular}

The fitness of the model in SEM-PLS is explained by various measures such as standardized root-mean-square residual (SRMR), and the exact model fits like d_ULS and d_G, Normed Fit Index (NFI), and $\chi^{2}$ (Chi-square). The model fit measures consisting of the measured value of both saturated model as well as the estimated model is reported in the table present below. The saturated model assesses the correlation between all constructs. The estimated model, on the other hand, takes model structure into account and is based on the total effect scheme. The measurement model has a good fit with the data (SRMR is 0.064, NFI is 0.793). The lower the SRMR the better the fit. By rule, a model has a good fit when SRMR is less than 0.8 (Hu, 1998). (Refer Table 6).

4.8 Assessment of Hypothesized Model

Table 7. Mean, Standard Deviation, T and P values

\begin{tabular}{|c|c|c|c|c|c|}
\hline & Original Sample (O) & Sample Mean (M) & Standard Deviation (STDEV) & T Statistics (|O/STDEV|) & P Values \\
\hline CAW->ER & 0.059 & 0.052 & 0.096 & 0.617 & 0.537 \\
\hline EE->CAW & 0.162 & 0.143 & 0.084 & 1.918 & 0.056 \\
\hline EE->ER & 0.013 & -0.008 & 0.088 & 0.143 & 0.887 \\
\hline EE->GWB & 0.171 & 0.158 & 0.087 & 1.980 & 0.048 \\
\hline $\mathbf{E E}->\mathbf{J S}$ & 0.338 & 0.322 & 0.094 & 3.576 & 0.000 \\
\hline EE ->PsyCap & 0.815 & 0.818 & 0.027 & 29.663 & 0.000 \\
\hline GWB-> ER & -0.020 & -0.029 & 0.105 & 0.189 & 0.850 \\
\hline
\end{tabular}




\begin{tabular}{lrllll}
\hline JS->ER & 0.638 & 0.677 & 0.106 & 5.998 & 0.000 \\
PsyCap->CAW & 0.619 & 0.641 & 0.080 & 7.706 & 0.000 \\
PsyCap-> GWB & 0.658 & 0.670 & 0.084 & 7.814 & 0.000 \\
PsyCap-> JS & 0.496 & 0.516 & 0.089 & 5.597 & 0.000 \\
\hline
\end{tabular}

All study hypotheses were supportive, presenting statistically positive path coefficients, except GWB on ER, $(T>1.96$ and $p<0.05)$. In size effect, EE has higher path coefficients for ER at 0.887 and GWB has a higher path coefficient for ER at 0.850. All the research hypothesized direct relationship was supportive except with a slight significant low effect of $\mathrm{EE}$ on $\mathrm{ER}$ at $\mathrm{P}$ values $=0.887$ and GWB on $\mathrm{ER}$ at $\mathrm{p}$ value $=0.850$. Likewise, with the former literature on work engagement, it was identified that $\mathrm{EE}$ has a positive effect on GWB $(\mathrm{P}=$ $0.048, p<0.01)$ and on PsyCap $(p=0.000, p>0.001)$. However, GWB has a negative path coefficient of 0.20 on ER in the current study and a p-value of 0.850 , which is greater than 0.50. (Refer Table 7).

Here, we accept $H 1$ as EE has a moderately positive effect on $\mathrm{ER}$ at $\mathrm{P}$ value $=0.887$. Engaged employees plan to stay in an organization more often than unengaged employees do as per (Konrad, 2006). Because of the increased cognitive, emotional and behavior engagement, employees have a high level of organizational satisfaction and lower turnover intentions. When employees are more attached towards any organization they do not tend to quit easily.

\subsection{Test of Mediation}

To examine the mediation effect of PsyCap, CAW, GWB and JS, two models were compared, one of which includes mediating effect and another one depicts direct total effect among variables.

Table 8. Hypothesis testing: effects of path estimates

\begin{tabular}{lll}
\hline Structural Paths & Indirect Effects & Direct Effects \\
\hline EE ->PsyCap-> CAW & 0.504 & - \\
EE -> CAW -> ER & 0.010 & - \\
Psy Cap ->CAW->ER & 0.037 & - \\
EE->PsyCap ->CAW->ER & 0.030 & - \\
EE -> GWB ->ER & -0.003 & - \\
PsyCap -> GWB ->ER & -0.013 & - \\
EE->PsyCap -> GWB -> ER & -0.011 & - \\
EE -> JS -> ER & 0.215 & - \\
PsyCap -> JS -> ER & 0.316 & - \\
EE ->PsyCap -> JS ->ER & 0.258 & - \\
\hline
\end{tabular}




$\begin{array}{lll}\text { EE ->PsyCap - GWB } & 0.536 & - \\ \text { EE ->PsyCap -> JS } & 0.404 & - \\ \text { CAW -> ER } & - & 0.059 \\ \text { EE->CAW } & - & 0.666 \\ \text { EE->ER } & - & 0.511 \\ \text { EE->GWB } & - & 0.708 \\ \text { EE -> JS } & - & 0.742 \\ \text { EE ->PsyCap } & - & 0.815 \\ \text { GWB -> ER } & - & -0.020 \\ \text { JS ->ER } & - & 0.638 \\ \text { PsyCap ->CAW } & - & 0.619 \\ \text { PsyCap ->ER } & - & 0.340 \\ \text { PsyCap ->GWB } & - & 0.658 \\ \text { PsyCap ->JS } & - & 0.496\end{array}$

H2. PsyCap will positively mediate the relationship between employee engagement and CAW

By including a direct path from EE to CAW, the first substitute model was examined for statistical analysis. Though not hypothesized, it is implicit that EE can certainly influence employees level of CAW as the correlation coefficient was strong at $(\mathrm{r}=0.666)$. The higher the engagement level at work the more control employees will have there. The path coefficient from EE to CAW in our analysis is 0.16 , which is a highly positive correlation among these two variables. In the first alternative model, with PsyCap as a mediating variable the path coefficient is $0.504, \mathrm{t}=6.937, \mathrm{p}=0.000$. The results of the mediation analysis discovered that PsyCap fully mediates the relationship between EE and CAW. EE has both direct and indirect effects on CAW. Here, we accept $H 2$ as PsyCap positively mediates the relationship between EE and CAW. It is also supported by (Nguyen, 2012). Their research finding showed that psychologically competent individuals have personal assets and they do not depend on external resources. This advantage enables them to have more control over their work in hard times, which improves their engagement level.

H3. PsyCap and GWB will positively mediate the relationship between employee engagement and employee retention

There exists a positive direct relationship between PsyCap and GWB. The level of hope, resilience, optimism and efficacy of workers would definitely and directly affect their overall life satisfaction. The direct path from PsyCap to GWB has a path coefficient $=0.658, \mathrm{t}=$ 7.814 and $p=0.000$ which is significant. However, GWB does not mediate the relationship between EE and ER and PsyCap and ER and shows a negative correlation as mentioned above. Hence, we fail to accept $H 3$. 
H4. PsyCap and JS will positively mediate the relationship between employee engagement and employee retention

Adding a direct path from $\mathrm{EE}$ to $\mathrm{ER}$, the path coefficient $=0.511, \mathrm{t}=8.587, \mathrm{p}=0.000$ which is a significant positive relationship between these two variables. The direct path results from PsyCap to JS having the path coefficient $=0.496, t=5.597$ and $p=0.000$. In the alternative model, with PsyCap and JS as mediating variables for EE and ER, the path coefficient = $0.258, \mathrm{t}=4.326, \mathrm{p}=0.000$, the results of the mediation study discovered that PsyCap and JS positively mediates the relationship between EE and ER. Hence, we accept $H 4$.

H5. PsyCap will positively mediate the relationship between employee engagement and GWB

Adding a direct path from $\mathrm{EE}$ to GWB, the path coefficient $=0.708, \mathrm{t}=17.396$ and $\mathrm{p}=0.000$. In the alternative model, with PsyCap as the mediating variable, the path coefficient $=0.536$, $\mathrm{t}=7.485$ and $\mathrm{P}=0.000$, the results of the mediation study identified that PsyCap positively mediates the relationship between EE and GWB. Thus the direct as well as in direct effect is significant and we accept $H 5$.

H6. PsyCap will positively mediate the relationship between employee engagement and JS Adding a direct path from EE to JS, the path coefficient $=0.742, t=18.784$ and $p=0.000$. In the alternative model, with PsyCap as mediating variable the path coefficient $=0.404, \mathrm{t}=$ 5.340 and $\mathrm{P}=0.000$, the results of the mediation study discovered that PsyCap positively mediates the relationship between EE and JS. Thus, the direct as well as in direct effect is significant. In sum, PsyCap played an essential role not only for EE and JS but for GWB as well. Hence, we accept H6.

H7. GWB will positively mediate the relationship between employee engagement and employee retention

Adding a direct path from EE to ER, the path coefficient $=0.511, t=8.587, p=0.000$, in the alternative model, with GWB as mediating variable, the path coefficient is $-0.003, t=0.175$ and $\mathrm{P}=0.861$, the results of the mediation study identified that GWB negatively mediates the relationship between EE and ER. Thus the direct effect is significant and indirect is not. As mentioned above there exists a negative relation between GWB and ER as per statistical analysis. Hence, we fail to accept $H 7$. It is not necessary that employees with high GWB stay in a similar organization for a longer period of time as millennials now a day's tend to leave every organization in two years for better prospects.

H8. GWB will positively mediate the relationship between PsyCap and employee retention

By including a direct path from PsyCap to ER, the path coefficient $=0.340, t=3.800 \mathrm{p}=$ 0.000 . In the alternative model, with GWB as the mediating variable the path coefficient is $0.013, \mathrm{t}=0.183$ and $\mathrm{P}=0.855$, the results of the mediation study revealed that GWB negatively mediates the relationship between PsyCap and ER. Thus the direct effect is significant and indirect is not. Hence, we fail to accept $H 8$.

H9. CAW will positively mediate the relationship between employee engagement and employee retention

Adding a direct path from $E E$ to $E R$, the path coefficient $=0.511, t=8.587, p=0.000$. In the second alternative model, with CAW as mediating variable the path coefficient is $=0.010, \mathrm{t}=$ 
$0.591, p=0.555$, the results of the mediation study identified that CAW fully mediates the relationship between EE and ER. Hence, it can be said that EE has both direct and indirect effects on ER. Here, we accept H9. (Kanten, 2012) suggested that EE has a positive major relationship with positive behavior at work as these employees are vigilant and energetic at work in a way that they manage their work and which in turn this leads to retention.

H10. CAW will positively mediate the relationship between PsyCap and employee retention

By including a direct path from PsyCap to ER, the path coefficient $=0.340, t=3.800 \mathrm{p}=$ 0.000. In the third alternative model, with CAW as mediating variable the path coefficient is $0.037, \mathrm{t}=0.591, \mathrm{p}=0.557$, the results of the mediation analysis discovered that CAW fully mediates the relationship between PsyCap and ER. Here, we accept the H10. As per previous literature PsyCap positively influences CAW and in turn may improve employee retention.

H11. PsyCap and CAW will positively mediate the relationship between employee engagement and employee retention

Adding a direct path from EE to $E R$, the path coefficient $=0.511, t=8.587, p=0.000$ which is a significant positive relationship between these two variables. The direct path results from PsyCap to CAW has the path coefficient $=0.619, \mathrm{t}=7.706$ and $\mathrm{p}=0.000$. In the alternative model, with Psycap and CAW as mediating variable the path coefficient $=0.030, t=0.584, p$ $=0.560$, the results of the mediation analysis discovered that PsyCap and CAW positively mediates the relationship between EE and ER. Hence, we accept $H 11$.

H12. JS will positively mediate the relationship between employee engagement and employee retention

Adding a direct path from $E E$ to $E R$, the path coefficient $=0.511, t=8.587, p=0.000$. In the alternative model, with JS as mediating variable the path coefficient $=0.215, t=2.613$ and $p$ $=0.009$, the results of the mediation analysis discovered that JS positively mediates the relationship between EE and ER. Hence it can be said that EE has both direct and indirect effects on ER through JS and we accept H12.The total effects including the direct and indirect (mediating) effects are summarized in table VIII.

H13. JS will positively mediate the relationship between PsyCap and employee retention

By including a direct path from PsyCap to ER, the path coefficient $=0.340, t=3.800 \mathrm{p}=$ 0.000 . In the alternative model, with JS as mediating variable the path coefficient is $=0.316, \mathrm{t}$ $=4.502$ and $\mathrm{P}=0.000$, the results of the mediation analysis discovered that JS positively mediates the relationship between PsyCap and ER. Thus, the direct as well as in direct effect is significant. Hence, we accept $H 13$.

\section{Discussion}

\subsection{Research Findings}

The results obtained fully support $H 1, H 2, H 4 H 5, H 6, H 9, H 10, H 11, H 12$ and H13. In contrast, regarding $H 3, H 7$ and $H 8$, the mediating relationships were negative and we are unable to accept these hypotheses. Considering mutually, the results of the current research provide empirical facts for the points from (Bakker, 2008) that personal resources in the form of PsyCap can optimistically relate to the level of work engagement. The research validates the study in a way that it supported the idea of engaged employees being easily able to be retained, Furthermore employees with a high level of PsyCap does possess CAW and JS that 
again affects the turnover intentions of employees. The result further supports the study of (Kanten, 2012) EE has a constructive major relationship with positive behavior at work as workers with high level of engagement are quite alert and energetic at work. They control their work, which in turn leads to retention of these employees because they know how to control a stressful situation and pressure at work and how to be positive about the new changes at work life. It is not necessary that employee with a high level of GWB intend to stay in a single company for a longer period of time, GWB does not guarantee employee loyalty to one company which is also backed by the result of the study that GWB does not positively mediates the relationship between EE and ER and between PsyCap and ER.

The study further validates the findings of (Xanthopoulou, 2009) about positive relation between EE and PsyCap. Engaged employee's posses' positive feelings about their work and are emotionally attached towards their work which increases their self-efficacy, hope, optimism and resilience. Also, it supports the study by (Avey J. W., 2008), which empirically depicts the direct relationship between PsyCap and EE. Workers that have a high level of self-efficacy and optimism with demanding goals are expected to be extra internally motivated and engaged in their jobs.

However, a small number of studies examined the relationship between PsyCap, CAW, GWB and JS. The outcomes of the current study further extended the findings of (Nguyen, 2012) that PsyCap has a positive relationship with workers behaviors by giving insights into CAW and GWB. Several studies found the positive relationship between PsyCap and GWB, however, these both together did not mediate positively between EE and ER as per our result. These results are in accordance with the available literature discussed above. Engaged individuals are entirely concerned and passionate about their jobs and organizations and they are willing to be able to add more towards organization's success. Furthermore, the results also suggest that the employees with elevated intensity of optimism and self-efficacy along with demanding objectives are fundamentally motivated and emotionally, cognitively and physically engaged in their jobs. Moreover, they, demonstrate characters that are not only related to fulfillment, which results productively, but also career satisfaction.

The essential contribution of this research lies in establishing the mediating role of PsyCap, CAW, GWB and JS between EE and ER which was never examined earlier. In that case, all variables are positively mediating except GWB between EE and ER and Between PsyCap and ER.

\subsection{Theoretical Contribution}

This research is linked to the rising constructs in HR, OB, and Psychology. This study examined five positive organizational behaviors simultaneously. One of the contributions of this study lies in identifying the fact that EE and PsyCap are antecedents of JS. It means that the employees with a high level of efficacy, resilience, hope and optimism tend to have high level of EE, which results into work satisfaction and happiness and high retention. This study will guide in further extension of the research on the same topic in the future. This research can be helpful for managers and organizations to understand how to come up and devise strategies that can help to increase employee engagement and why change is required to devise policies on work life balance, new task assignment, training and development. 


\section{Conclusion}

In this research, we tried to understand the relationship between employee engagement and employee retention through the mediating role of psychological capital, control at work, general well-being and job satisfaction. The result of the study showed a positive relationship among variables except for GWB's role between EE and ER and PsyCap and ER. The role of employee engagement cannot be neglected by any organizations in today's era, where employee's demands keep changing and they need to be engaged in order to be retained happy. Several other factors impact the level of engagement and retention in the organizations. This research further improved the findings of (Gupta, 2018), as it has been revealed that PsyCap fully mediates between EE and GWB as per results. Whereas, interpretations of (M. Gupta, 2018) for finding the relationship among WE, GWB and CAW were based on the correlation values. This study goes a step ahead and provides the extent to which WE is associated to GWB and CAW. PsyCap has been found impacting notably on both GWB and CAW.

\subsection{Limitation and Future Direction}

The present study is not exclusive of limitations. This study relied on self-reported answers by employees who volunteered to contribute, so common method bias is anticipated. Though, all variables can be measured by individual perceptions. Furthermore, focusing the study on Pakistan, the sample of the study is likely to be limited with certain groups with similar demographic characteristics.

\section{References}

Agarwala, T. (2003). Innovative human resource practices and organizational commitment: an empirical investigation. International Journal of Human Resource Management, 175-198. https://doi.org/10.1080/0958519021000029072

Avey, J. L. (2010). Impact of positive psychological capital on employee well-being over time. Journal Of Occupational Health Psychology, 17-28. https://doi.org/10.1037/a0016998

Avey, J. W. (2008). Can positive employees help positive organization change? Impact of psychological capital and emotions on relevant attitudes and behaviors. Journal of Applied Behavioral Sciences. https://doi.org/10.1177/0021886307311470

Bahreini. (2015, October 19). Employee engagement is more important than the customers. Entrepreneur asis pacific, p. 2.

Bakker, A. A. (2008). Towards the model of work engagement. Career Development International, 209-223. https://doi.org/10.1108/13620430810870476

Bushra, A. (2012). Job Satisfaction and Women's Turnover Intentions in Pakistan's Public Universities. The Lahore Journal of Business, 59-77. https://doi.org/10.35536/ljb.2012. v1.i1.a4

Carmine, E. A. (1979). Reliability and validity assessment. Sage Publications, Newbury Park, 51. https://doi.org/10.4135/9781412985642

Cates, K. A. (2003). Algebra lessons for older workers. In J. Pickford (Ed.) Mastering People Management. Harlow: FT Prentice Hall.

Chin, W. W. (1998). Issues and opinion on structural equation modeling. MIS Quarterly. 


\section{MInstitute Macrothink $_{\text {Int }}$}

Christopher, J. (1999). Situating psychological well-being: exploring the cultural roots of its theory and research. Journal of Counseling and Development, 141-152. https://doi.org/ 10.1002/j.1556-6676.1999.tb02434.x

Daskalakis, S. (2008). Evaluating the impact of a service oriented framework for healthcare interoperability. Studies in Health Technology and Informatics.

de Lange, A. D. (2008). Should I stay or should I go? Examining longitudinal relations among job resources and work engagement for stayers versus movers. Work and Stress, 201-223. https://doi.org/10.1080/02678370802390132

Diener, E. (1984). Subjective well-being. Psychological Bulletin, 542-575. https://doi.org/ 10.1037/0033-2909.95.3.542

Diener, E. B.-D. (2008). Happiness: Unlocking the mysteris of psychological waelth,. Blackwell Publishing, Malden,MA. https://doi.org/10.1002/9781444305159

Easton, S. (2013). QoWL(quality of working life) - what, how, and why. Psychology Research, 596-605.

Erdagon, B. B. (2012). Whistle while you work are view of the life satisfaction literature. Journal of Management, 1038-1083. https://doi.org/10.1177/0149206311429379

Festing, M. A. (2014). Generational challenges to talent management: a framework for talent retention based on the psychological-contract perspective. Journal of World Business, 262-71. https://doi.org/10.1016/j.jwb.2013.11.010

Fredrickson, B. (2009). Positivity. Crown, New York, NY.

Gattiker, U. A. (1988). Predictors for managers career mobilit, success and satisfaction. Human Relations, 569-591. https://doi.org/10.1177/001872678804100801

Ghosh, P. S. (2013). Who stays with you? Factors predicting employees' intention to stay. International Journal of Organizational Analysis, 288-312. https://doi.org/10.1108/IJOASep-2011-0511

Gruneberg, M. M. (1979). Understanding Job Satisfaction. New York: MaCmillan. https://doi.org/10.1007/978-1-349-03952-4

Gupta, M. A. (2017). The relationship between psychological capital and turnover intention: workengagement as mediator andworkexperience asmoderator. Jurnal 1Pengurusan (UKM Journal of Management), 117-126. https://doi.org/10.17576/pengurusan-2017-49-10

Gupta, M. A. (2018). Does work engagement enhance general well-being and control at work? Mediating role of psychological capital. Evidence-based HRM: a Global Forum for Empirical Scholarship. https://doi.org/10.1108/EBHRM-05-2017-0027

Gupta, M. S. (2018). Does work engagement enhance general well-being and control at work? Mediating role of psychological capital . Evidence based HRM: a global forum for empirical schloarship. https://doi.org/10.1108/EBHRM-05-2017-0027

Gupta, V. A. (2016). The relationships between perceived organizational support, affective commitment, psychological contract breach, organizational citizenship behaviour and work engagement. Journal of Advanced Nursing, 2806-2817. https://doi.org/10.1111/jan.13043

Guthrie, J. F. (2009). High performance work systems in Ireland: human resource and organizational outcomes. International Journal of Human Resource Management, 112-125. 
https://doi.org/10.1080/09585190802528433

Harter, J. S. (2002). Business-unit-level relationship between employee satisfaction, employeeengagement, andbusinessoutcomes: ameta-analysis. JournalofApplied Psychology, 268-279. https://doi.org/10.1037/0021-9010.87.2.268

Hu, L.-T. (1998). Fit indices in covariance structure modeling: Sensitivity to underparameterized model misspecification. Psychological Methods, 424-453. https://doi.org/10.1037/1082-989X.3.4.424

Judge T. A (1995). The big five personality traits, general mental ability and career sucess across the life span. Personnel Psychology, 621-651.

Judge, T. C. (1995). An empirical investigation of the predictors of executive career success. Personnel Psychology, 485-519. https://doi.org/10.1111/j.1744-6570.1995.tb01767.x

Kahn, W. (1990). Psychological conditions of personal engagement and disengagement at work. Academy of Management Journal, 621-651. https://doi.org/10.5465/256287

Kanten, S. S. (2012). An empirical research on relationship quality of work life and work engagement. Procedia - Social and Behavioral Sciences, 360-366. https://doi.org/10.1016/ j.sbspro.2012.09.057

Konrad, A. M. (2006). Engaging employees through highinvolvement work practices. Ivey Business Journal Online.

Kyndt, E. D. (2009). Employee retention: organizational and personal perspectives. Vocations and Learning, 195-215. https://doi.org/10.1007/s12186-009-9024-7

Law, K. W. (1998). Toward a taxonomy of multidimensional constructs. Academy of Management Review, 741-753. https://doi.org/10.5465/amr.1998.1255636

Lee. H. Y. (2009). The moderating effects of organizational culture on the relationships between leadership behaviour and organizational commitment and between organizational commitment and job satisfaction and performance. Leadership \& Organization Development Journal, 53-86. https://doi.org/10.1108/01437730910927106

Lounsbury, J. L. (2003). An investigation of personality traits in relation to career satisfaction. Journal of Career Assesment, 287-307. https://doi.org/10.1177/1069072703254501

Luthans. (2013). Meeting the leadership challenge of employee well-being through relationship PsyCap and health PsyCap. Journal of leadership \& organizational studies, 118-113. https://doi.org/10.1177/1548051812465893

Luthans, F. A. (2004). Human, social, and now positive psychological capital. Organizational, 143-160. https://doi.org/10.1016/j.orgdyn.2004.01.003

Luthans, F. Y. (2007). Psychological Capital: Developing the Human Competitive Edge. Oxfor University Press.

Luthans, K. L. (2016). A positive approach to management education: the relationship between academic PsyCap and student engagement. Journal of Managemnt Development, 1098-1118. https://doi.org/10.1108/JMD-06-2015-0091

Lyubomirski. (2001). Why are some people happier than others? The role of cognitive and motivational processes in well-being. American Psychologist, 239-249.

MacLeod, D. A. (2009). Engaging for Success: Enhancing Performance Through Employee 


\section{Macrothink}

Human Resource Research

ISSN 1948-5441 2020, Vol. 4, No. 1

Engagement. Norwich: Office of Public Sector Information. https://doi.org/10.1037/e576512 011-001

Maslach, C. S. (2001). Job Burnout. Annual Review of Psychology, 397-422. https://doi.org/10.1146/annurev.psych.52.1.397

Mitchell, T. R. (2001). Why People Stay: Using Job Embeddedness to Predict Voluntary Turnover. Academy of Management Journal, 1102-1121. https://doi.org/10.2307/3069391

$\mathrm{Ng}, \mathrm{T}$. E. (2005). Predictors of objective and subjective career success: a meta-analysis. Personnel Psychology, 367-408. https://doi.org/10.1111/j.1744-6570.2005.00515.x

Nguyen, T. (2012). Psychological capital,quality of work life, and quality of life of marketers evidence from Vietnam. Journal of Macromarketing, 87-95. https://doi.org/10.1177/027 6146711422065

Palmer, R. A. (2012). The impact of emotionally intelligent leadership on talent retention, discretionary effort and employment brand. Industrial and Commercial Training, 9-18. https://doi.org/10.1108/00197851211193372

Richman, A. (2006). Everyone wants an engaged workforce how can you create it. Workspan, 36-39.

Schaufeli, W. A. (2004). Job demands, job resources, and their relationship with burnout and engagement: a multi-sample study. Journal of Organizational Behavior, 293-315. https://doi.org/10.1002/job.248

Schaufeli, W. T. (2006). Dr Jekyll and Mr Hyde: On the differences between work engagement and workaholism. Edward Elgar, Northampto, 193-252. https://doi.org/10.4337/ 9781847202833.00018

Schuler, R. J. (2011). Framework for global talent management: HR actions for dealing with global talent challenges. In H. Scullion and D.G. Collings (eds) Global Talent Management. Abingdon: Routledge.

Seashore, S. L. (1982). Observing and Measuring ORganizational Change, A Guide to Practice. Newyork:Wiley.

Sheridan, J. E. (1992). Organziational culture and employee retention. Academy of Managemnt Journal. https://doi.org/10.2307/256539

Shuck. (2011). Integratvie literature review:four emerging perspective of employee engagement. Human Resource Development, 304-328. https://doi.org/10.1177/1534484311 410840

Stringer, L. (2006). The Link between the quality of the supervisor employee relationship and the level of the employees's job satisfcation. Public Organization Review, 125-142. https://doi.org/10.1007/s11115-006-0005-0

Sumardi, W. A. (2010). The three facets of talent management in Malaysia. International Journal of Business Research, 181-185.

Tinline, G. A. (2010). Improving employee engagement and wellbeing in an NHS trust. Strategic HR Review, 19-24. https://doi.org/10.1108/14754391011022226

Torp, S. G. (2013). Work engagement: a practical measure for workplace health promotion. Health Promotion International, 387-396. https://doi.org/10.1093/heapro/das022 


\section{Macrothink}

Human Resource Research

ISSN 1948-5441 2020, Vol. 4, No. 1

Vigoda, E. (2000). Organizational politics,job attitudes, and workoutcomes:explorationand implications for the public sector. Journal of Vocational Behavior, 326-47. https://doi.org/10.1006/jvbe.1999.1742

Weigl, M. H. (2010). Work engagement accumulation of task, social, personal resources: a three-wave structural equation model. Journal of Vocational Behavior, 140-153. https://doi.org/10.1016/j.jvb.2010.03.002

Weimann, J. K. (2015). Measuring Happiness: The Economics of Well-Being. MIT Press, Cambridge, $M A$. https://doi.org/10.7551/mitpress/10036.001.0001

Wright, T. R. (2004). State and trait correlates of job performance: atale of two perspective. Journal of Business and Psychology, 521-537.

Xanthopoulou, D. B. (2009). "Reciprocal relationships between job resources, personal resources, and work engagement. Journal of Vocational Behavior, 235-244. https://doi.org/10.1016/j.jvb.2008.11.003

Zelenski, J. M. (2008). The happy-productive worker thesis revisited. Journal of Happiness Studies, 521-537. https://doi.org/10.1007/s10902-008-9087-4

\section{Copyright Disclaimer}

Copyright for this article is retained by the author(s), with first publication rights granted to the journal.

This is an open-access article distributed under the terms and conditions of the Creative Commons Attribution license (http://creativecommons.org/licenses/by/3.0/). 